\title{
Influence of Gender on Arrhythmia Characteristics and Outcome in the Multicenter UnSustained Tachycardia Trial
}

\author{
ANDREA M. RUSSO, M.D.,* NICHOLAS J. STAMATO, M.D., † MICHAEL H. LEHMANN, M.D., $\ddagger$ \\ GAIL E. HAFLEY, M.S., $₫$ KERRY L. LEE, PH.D., $₫$ KAREN PIEPER, M.S., \\ ALFRED E. BUXTON, M.D. $§$ and the MUSTT Investigators
}

From the * University of Pennsylvania Health System, Philadelphia, Pennsylvania, USA; $\nmid$ SUNY Upstate Medical University, Syracuse, New York, USA; †University of Michigan Health System, Ann Arbor, Michigan, USA; IDuke University, Durham, North Carolina, USA; and $§$ Brown Medical School, Providence, Rhode Island, USA

\begin{abstract}
Influence of Gender in MUSTT. Introduction: Previous studies have demonstrated gender differences in risk of sudden death in patients with ischemic heart disease. The Multicenter UnSustained Tachycardia Trial (MUSTT) evaluated the ability of therapy guided by electrophysiologic (EP) testing to reduce mortality in patients with coronary disease, ejection fraction $\leq \mathbf{4 0 \%}$, and spontaneous nonsustained ventricular tachycardia.

Methods and Results: We analyzed the influence of gender on results of EP testing and outcome of patients enrolled in MUSTT. Women made up $14 \%$ of the overall MUSTT population and were less likely than men to have inducible sustained randomizable ventricular arrhythmias $(24 \%$ vs $36 \%, \mathrm{P}<0.001)$. Baseline characteristics differed between men and women. In randomized patients, women were older, more likely to have had an infarction within 6 months, more likely to have a history of heart failure, and more likely to have recent angina prior to enrollment than men $(\mathbf{P}<\mathbf{0 . 0 5})$. In the EP-guided therapy group, there was no difference in implantable cardioverter defibrillator implantation rate in men and women $(45 \% \mathrm{vs} 53 \%$, $\mathbf{P}=\mathbf{0 . 3 8}$ ). There also were no significant gender influences on risk of arrhythmic death or cardiac arrest (2-year event rate $9 \%$ in women and $12 \%$ in men, adjusted hazard ratio 0.88 ) or overall mortality (2-year event rate $32 \%$ in women vs $21 \%$ in men, adjusted hazard ratio 1.51 ).

Conclusion: The outcome and benefit of EP-guided therapy in this trial did not appear to be influenced by gender. However, due to the small numbers of women in the trial, small differences in outcome may not be apparent. Plans for future primary prevention trials should include careful risk stratification of women who less often have inducible sustained ventricular arrhythmias and better left ventricular function despite more frequent heart failure. (J Cardiovasc Electrophysiol, Vol. 15, pp. 993-998, September 2004)
\end{abstract}

arrhythmia, coronary disease, death sudden, tachycardia, gender

\section{Introduction}

Previous studies have raised concern regarding possible gender bias with respect to evaluation and treatment of cardiovascular disease, including referral for diagnostic cardiac catheterization, thrombolytic therapy for acute myocardial infarction (MI), and revascularization procedures for coronary artery disease. ${ }^{1-6}$ Women have greater morbidity and mortality associated with MI. ${ }^{7}$ It has been suggested that there is gender bias in referral for invasive treatment, and this

This research was partly funded by grants from the National Heart, Lung and Blood Institute, and Metronic, Guidant, Boehringer-Ingelheim and Wyeth-Ayerst.

This manuscript was processed by guest editor David S. Cannom, M.D. E. Prystowsky recused himself from the review process because he is one of the MUSTT Investigators.

Address for correspondence: Andrea M. Russo, M.D., University of Pennsylvania Health System, Presbyterian Medical Center, Fourth Floor PHI, 38th and Market Streets, Philadelphia, PA 19104. Fax: 215-243-3264; E-mail: andrea_russo@uphs.upenn.edu

Manuscript received 29 January 2004; Accepted for publication 8 April 2004.

doi: 10.1046/j.1540-8167.2004.04050.x may have an impact on outcome. However, these gender differences in referral for invasive procedures or differences in outcome are explained, at least in part, on the basis of age, severity of coronary disease, or presence of other concomitant risk factors. ${ }^{7-10}$

Gender differences in the incidence of sudden death and risk factors for development of sustained ventricular arrhythmias have been previously described. ${ }^{11,12}$ The incidence of sudden cardiac death is lower in women than in men, comprising one third of all coronary heart disease deaths in women compared to one half in men. ${ }^{11}$ There appears to be a 20 -year lag in the incidence of sudden cardiac death in women in comparison to men. ${ }^{12}$ This may be due to the protective effects of sex steroids on development of coronary artery disease.

The Multicenter UnSustained Tachycardia Trial (MUSTT) was a primary prevention trial that demonstrated the benefit of electrophysiologically (EP)-guided therapy for patients with coronary artery disease, reduced left ventricular function, and asymptomatic nonsustained ventricular tachycardia (NSVT). ${ }^{13}$ Patients with inducible sustained ventricular tachycardia (VT) had a high mortality rate, which was lowered by treatment with implantable cardioverter defibrillators (ICDs) but not by antiarrhythmic drug therapy. The purpose of the current analysis was to determine the influence of gender on patient characteristics, treatment, and outcome of patients enrolled into this trial. 


\section{Methods}

The MUSTT protocol has been described previously. ${ }^{13,14}$ This was a National Institutes of Health-sponsored, multicenter, randomized trial that evaluated the role of EP-guided antiarrhythmic therapy in patients with inducible sustained ventricular arrhythmias. Patients were eligible for enrollment if they had coronary artery disease, left ventricular ejection fraction (LVEF) $\leq 40 \%$, asymptomatic NSVT, and no history of spontaneous sustained VT, syncope, or cardiac arrest, except in the setting of an acute MI. Patients who had inducible sustained VT were randomized to a standard medical regimen, which included treatment with beta-blockers and angiotensin-converting enzyme inhibitors, versus the same regimen with the addition of EP-guided therapy. EP-guided therapy included antiarrhythmic drug treatment or ICD therapy for patients who did not respond to antiarrhythmic drugs at the time of EP testing.

Patients were eligible for randomization if they had sustained monomorphic VT that was reproducibly inducible with single, double, or triple extrastimuli, or with burst pacing. If sustained polymorphic VT was reproducibly inducible with single or double extrastimuli, patients were eligible for randomization. Patients who refused randomization after induction of sustained VT were followed in a registry. Patients without any inducible sustained ventricular arrhythmias also were followed in the registry. In addition, patients with sustained polymorphic VT inducible with triple extrastimuli were not eligible for randomization and were followed in a registry.

\section{Patients}

A total of 2,202 patients were enrolled in the trial at 85 sites, including 704 patients with inducible sustained VT who were randomized as described earlier. The remaining 1,498 patients were followed in a registry without antiarrhythmic therapy. ${ }^{13}$

\section{Statistical Analysis}

Values for continuous variables are presented as medians with 25th and 75th percentiles. Values for categorical variables are presented as percentages. Differences in clinical characteristics and discharge medications between gender groups were assessed using the Wilcoxon rank sum test (for continuous variables) and the Chi-square test (for categorical variables). All tests of significance were two tailed. Cumulative event rates and survival curves were calculated by the Kaplan-Meier method, and outcome differences were assessed with the log rank test. In addition, covariate-adjusted analyses of outcomes were performed with the Cox proportional hazards model. Covariates included in these analyses were the induction of randomizable VT, age, ejection fraction, race, prior bypass surgery, prior angioplasty, prior MI, number of vessels with $>75 \%$ stenosis, duration (in beats) of the longest episode of NSVT, symptoms of angina within 6 weeks of enrollment, left bundle branch block, intraventricular conduction delays, and use of digitalis at baseline. Hazard ratios and $95 \%$ confidence intervals also were calculated using the Cox proportional hazards model.
TABLE 1

Gender Differences in Enrollment: Randomized and Registry Patients

\begin{tabular}{lcc}
\hline & Men & Women \\
\hline Entire study $(\mathrm{N}=2,202)$ & $1,901(86 \%)$ & $301(14 \%)$ \\
Randomized $(\mathrm{N}=704)$ & $636(90 \%)$ & $68(10 \%)$ \\
Registry $(\mathrm{N}=1,498)$ & $1,265(84 \%)$ & $233(16 \%)$ \\
Inducible $(\mathrm{N}=101)$ & 91 & 10 \\
Noninducible $(\mathrm{N}=1,397)$ & 1,174 & 223 \\
\hline
\end{tabular}

\section{Results}

\section{Overall Population: Randomized Versus Registry}

A total of 301 women were enrolled in the trial, representing $14 \%$ of the total study population (Table 1). Ten percent of patients enrolled in the randomized group were women, whereas $16 \%$ of those in the registry were women $(\mathrm{P}=0.001)$. Enrollment refusal forms were received from 856 patients (660 men and 160 women). Of the patients who refused enrollment, $10 \%$ of women and $15 \%$ of men underwent a baseline EP study $(\mathrm{P}=0.083)$. For patients who underwent baseline EP testing in the enrollment refusal group, $86 \%$ of women and $65 \%$ of men had inducible sustained VT $(\mathrm{P}=0.098)$. For those who refused enrollment, $19 \%$ of women compared to $10 \%$ of men were non-Caucasian $(P=0.002)$. Sufficient information regarding specific reasons for enrollment refusal is not available to allow adequate comparisons between men and women.

\section{Baseline Characteristics}

Within the randomized group, there were no significant differences in LVEF, race, presence of three-vessel coronary artery disease, prior coronary artery bypass graft or other revascularization, ECG conduction delays, or left ventricular hypertrophy between men and women (Table 2). Women were older, more likely to have had an MI within 6 months of enrollment, more likely to have experienced angina within 6 weeks prior to enrollment, and less likely to have atrial fibrillation than men.

Within the registry, there were no significant differences with regard to age, presence of three-vessel coronary artery disease, or percentage of patients who experienced angina within 6 weeks prior to enrollment in men and women. However, women had a higher LVEF and were more often nonCaucasian, less likely to have undergone prior coronary artery bypass graft or other revascularization, more likely to have suffered an MI within 6 months of enrollment, and more likely to have a left bundle branch block than men (Table 2).

Although data regarding the clinical history of congestive heart failure (CHF) were not collected on all patients, for patients in whom data were available, there was a significant difference in the prevalence of CHF between men and women in the randomized group. In the randomized patients, $88 \%$ of females and $69 \%$ of males had a history of CHF $(P=0.008)$. In registry patients, $75 \%$ of females and $67 \%$ of males had a history of $\mathrm{CHF}(\mathrm{P}=0.111)$.

\section{EP Testing}

Men were more likely to have inducible sustained VT than women. Thirty-six percent of men versus $24 \%$ of women had inducible randomizable VT $(\mathrm{P}=0.001)$. It should be noted 
TABLE 2

Clinical Characteristics of the Patients at Baseline

\begin{tabular}{|c|c|c|c|c|c|c|}
\hline & \multicolumn{3}{|c|}{ Randomized } & \multicolumn{3}{|c|}{ Registry } \\
\hline & $\operatorname{Men}(\mathbf{n}=636)$ & Women $(n=68)$ & P Value & $\operatorname{Men}(\mathrm{n}=1,265)$ & Women $(\mathbf{n}=\mathbf{2 3 3})$ & P Value \\
\hline Age $<70$ years & $67 \%$ & $53 \%$ & 0.022 & $66 \%$ & $67 \%$ & 0.77 \\
\hline Left ventricular ejection fraction $<30 \%$ & $51 \%$ & $44 \%$ & 0.30 & $51 \%$ & $44 \%$ & 0.046 \\
\hline Caucasian & $89 \%$ & $82 \%$ & 0.14 & $86 \%$ & $76 \%$ & 0.001 \\
\hline Three-vessel coronary artery disease & $43 \%$ & $39 \%$ & 0.58 & $39 \%$ & $34 \%$ & 0.14 \\
\hline Prior coronary artery bypass graft & $55 \%$ & $59 \%$ & 0.58 & $64 \%$ & $52 \%$ & 0.001 \\
\hline Prior revascularization* & $66 \%$ & $65 \%$ & 0.79 & $75 \%$ & $64 \%$ & 0.001 \\
\hline Myocardial infarction to enrollment $\leq 6$ months & $30 \%$ & $47 \%$ & 0.010 & $31 \%$ & $40 \%$ & 0.021 \\
\hline Angina last 6 weeks & $38 \%$ & $51 \%$ & 0.026 & $35 \%$ & $33 \%$ & 0.56 \\
\hline History of congestive heart failure & $69 \%(\mathrm{n}=372)$ & $88 \%(\mathrm{n}=43)$ & 0.008 & $67 \%(\mathrm{n}=670)$ & $75 \%(\mathrm{n}=115)$ & 0.111 \\
\hline \multicolumn{7}{|l|}{ ECG characteristics } \\
\hline Left bundle branch block & $6 \%$ & $5 \%$ & 0.76 & $5 \%$ & $11 \%$ & 0.001 \\
\hline Intraventricular conduction delay & $21 \%$ & $15 \%$ & 0.32 & $18 \%$ & $13 \%$ & 0.10 \\
\hline Atrial fibrillation & $6 \%$ & 0 & 0.044 & $9 \%$ & $8 \%$ & 0.70 \\
\hline Left ventricular hypertrophy & $37 \%$ & $34 \%$ & 0.61 & $46 \%$ & $46 \%$ & 0.94 \\
\hline
\end{tabular}

${ }^{*}$ Includes coronary artery bypass graft and percutaneous revascularization.

that the higher percentage of women in the registry is due at least in part to this higher noninducibility rate in women. There was no difference in the type of VT induced in the randomized group. Ninety percent of men and $91 \%$ of women had sustained monomorphic VT induced; the remainder had sustained polymorphic VT induced $(\mathrm{P}=\mathrm{NS})$. Similarly, in registry patients, there was no difference in the percentage of men or women who had inducible sustained monomorphic VT.

\section{Nonantiarrhythmic Medical Therapy}

In the EP-guided therapy group, women were more likely to be discharged on diuretic therapy than men (Table 3). Except for diuretic therapy, there were no other differences between men and women with respect to discharge nonantiarrhythmic medical therapy in the EP-guided therapy versus no EP-guided therapy group. In the registry, women were more likely to be discharged on calcium channel blockers, digoxin, diuretics, and nitrates than men $(\mathrm{P}<0.05$; Table 3$)$.

\section{Antiarrhythmic Drug Therapy}

Among patients randomized to EP-guided therapy, 32\% of women were discharged with pharmacologic antiarrhythmic therapy versus $46 \%$ of men $(\mathrm{P}=0.12)$. There were no significant differences between men and women with respect to the number of antiarrhythmic drug trials or percentage of men versus women who still had inducible sustained ventricular arrhythmias after the first and last antiarrhythmic drug trials in the EP-guided therapy group. There was no difference between men and women with regard to the type of antiarrhythmic agents utilized.

\section{Outcome: Arrhythmic Death or Cardiac Arrest}

There were no gender differences in event-free survival from arrhythmic death or cardiac arrest in either the randomized or the registry patients (Fig. 1, Table 4). Within the randomized group, there were no differences in survival free of arrhythmic death or cardiac arrest between men and women who received EP-guided therapy or in those who received no EP-guided therapy (Table 4).

\section{Outcome: Total Mortality}

There were no significant gender differences in all-cause mortality in either the randomized or the registry patients (Table 4, Fig. 2). There was a trend toward a slightly higher overall mortality in women compared to men in the registry (27\% vs 20\%) and those who received EP-guided therapy (32\% vs 21\%), although this was not significant (adjusted $\mathrm{P}=0.13$ and 0.15 , respectively). Within the randomized group, there were no differences in mortality between men and women who received EP-guided therapy and between men and women who received no EP-guided therapy. The interaction of treatment and gender was not significant $(\mathrm{P}=0.12)$.

TABLE 3

Discharge Medications

\begin{tabular}{|c|c|c|c|c|c|c|c|c|c|}
\hline & \multicolumn{3}{|c|}{$\begin{array}{l}\text { No Electrophysiologically } \\
\text { Guided Therapy }\end{array}$} & \multicolumn{3}{|c|}{$\begin{array}{l}\text { Electrophysiologically } \\
\text { Guided Therapy }\end{array}$} & \multicolumn{3}{|c|}{ Registry } \\
\hline & $\begin{array}{c}\text { Men } \\
(n=319)\end{array}$ & $\begin{array}{c}\text { Women } \\
(\mathbf{n}=\mathbf{3 4})\end{array}$ & $\begin{array}{c}\mathbf{P} \\
\text { Value }\end{array}$ & $\begin{array}{c}\text { Men } \\
(\mathbf{n}=317)\end{array}$ & $\begin{array}{c}\text { Women } \\
(\mathbf{n}=34)\end{array}$ & $\begin{array}{c}\mathbf{P} \\
\text { Value }\end{array}$ & $\begin{array}{c}\text { Men } \\
(\mathrm{n}=\mathbf{1 , 2 6 5 )}\end{array}$ & $\begin{array}{c}\text { Women } \\
(\mathbf{n}=\mathbf{2 3 3})\end{array}$ & $\begin{array}{c}\mathbf{P} \\
\text { Value }\end{array}$ \\
\hline Beta-blockers & $51 \%$ & $50 \%$ & 0.88 & $30 \%$ & $18 \%$ & 0.13 & $36 \%$ & $30 \%$ & 0.13 \\
\hline Angiotensin-converting enzyme inhibitors & $76 \%$ & $85 \%$ & 0.22 & $72 \%$ & $71 \%$ & 0.84 & $72 \%$ & $76 \%$ & 0.16 \\
\hline Aspirin & $62 \%$ & $71 \%$ & 0.35 & $63 \%$ & $71 \%$ & 0.37 & $62 \%$ & $56 \%$ & 0.10 \\
\hline Calcium channel blockers & $25 \%$ & $24 \%$ & 0.89 & $21 \%$ & $29 \%$ & 0.25 & $18 \%$ & $26 \%$ & 0.004 \\
\hline Digitalis & $53 \%$ & $59 \%$ & 0.50 & $50 \%$ & $65 \%$ & 0.11 & $55 \%$ & $63 \%$ & 0.030 \\
\hline Diuretics & $56 \%$ & $74 \%$ & 0.055 & $56 \%$ & $76 \%$ & 0.025 & $57 \%$ & $66 \%$ & 0.017 \\
\hline Nitrates & $43 \%$ & $53 \%$ & 0.26 & $38 \%$ & $50 \%$ & 0.18 & $40 \%$ & $49 \%$ & 0.020 \\
\hline
\end{tabular}


All Patients

Survival Free From Arrhythmic Death or Cardiac Arrest

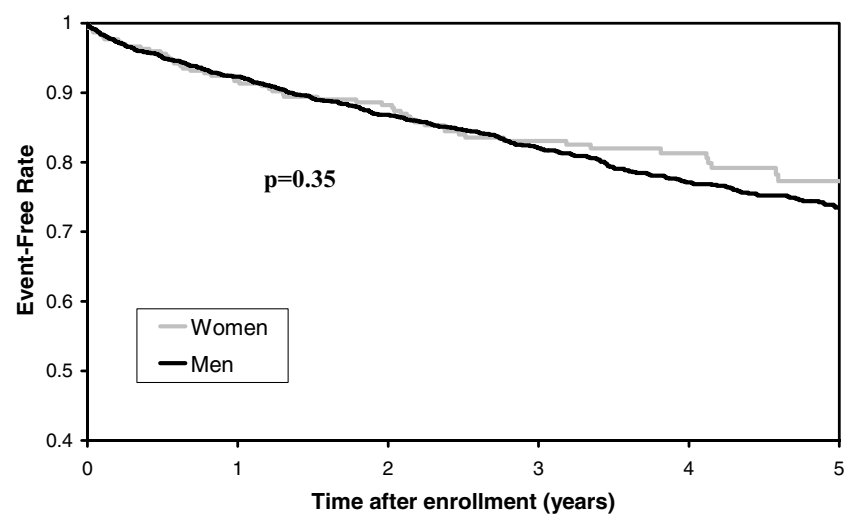

Figure 1. Survival free from arrhythmic death or cardiac arrest in all patients. There was no difference in 5-year survival free of arrhythmic death or cardiac arrest in men compared to women in the electrophysiologically guided therapy group $(P=0.35)$.

\section{Treatment: Type of EP-Guided Therapy and ICD Implantation}

The type of therapy prescribed to men and women in the EP-guided therapy group was examined. At the time of hospital discharge, there was no significant difference between women and men with respect to the percentage of patients for whom ICDs were recommended in the EP-guided therapy group (21/34 [62\%] patients vs $163 / 317$ [51\%] patients, $\mathrm{P}=0.25$ ). There was no difference in the patient refusal rate for ICD implantation in women versus men (3/34 [9\%] women vs 20/317 [6\%] men, $\mathrm{P}=0.79$ ).

At the time of hospital discharge, $45 \%$ of men and $53 \%$ of women had received ICDs in the EP-guided therapy group $(\mathrm{P}=0.38)$. An additional 41 men $(13 \%)$ received ICDs after hospital discharge; 23 were implanted after an event (cardiac arrest, sustained VT, or syncope), and the remaining 18 were implanted for unknown reasons. No women received ICDs after hospital discharge. Thus, a total of 58\% of men and 53\% of women had ICDs implanted at some point during the study $(\mathrm{P}=0.57)$.

\section{Discussion}

We have demonstrated that gender influences many important characteristics of patients enrolled in MUSTT. In spite of these differences, the risk of mortality and arrhythmic events in the trial appears to be similar for men and women. However, it should be recognized that a lack of power, particularly regarding arrhythmic events and mortality, could prevent identification of a significant difference in outcome, due to the small number of women enrolled.

The reason why a relatively small percentage of women was enrolled in this trial likely is related to the higher prevalence of coronary artery disease in men. A significantly higher percentage of women was enrolled in the registry compared to the randomized group, reflecting the lower rate of inducing randomizable VT in women. However, the contribution of a higher refusal rate of women for enrollment in the randomized group or physician bias cannot be excluded, because complete refusal data are not available. Enrollment refusal also may be confounded by racial differences, as a higher percentage of non-Caucasian women compared to men refused enrollment.

Gender differences in baseline characteristics have been identified previously in cardiac arrest survivors. ${ }^{15-18}$ Studies have shown that women cardiac arrest survivors have a lower prevalence of coronary disease and may have a higher LVEF than men. ${ }^{15-17}$ In the Antiarrhythmics Versus Implantable Defibrillator (AVID) trial, women were younger, more likely to have a nonischemic dilated cardiomyopathy, and more likely had ventricular fibrillation rather than VT as the index arrhythmia. ${ }^{15}$

In the current study, women in the randomized group were older and more likely to have experienced a recent MI or recent angina than men. The use of nonantiarrhythmic drugs, such as digitalis and diuretics, was higher in women. There was a significantly higher prevalence of a history of CHF in women compared to men in the randomized group. We also found that women were less likely to have inducible sustained ventricular tachyarrhythmias, which is similar to results of previous retrospective studies. ${ }^{16,17,19,20}$

TABLE 4

Two-Year and Five-Year Event Rates by Gender

\begin{tabular}{|c|c|c|c|c|c|c|}
\hline & \multicolumn{2}{|r|}{ Men } & \multicolumn{2}{|r|}{ Women } & \multirow[b]{2}{*}{$\begin{array}{c}\text { Adjusted* } \\
\text { Hazard Ratio (95\% CI) }\end{array}$} & \multirow[b]{2}{*}{$\begin{array}{c}\text { Adjusted }^{*} \\
\text { P Value }\end{array}$} \\
\hline & $\mathbf{N}$ & $\begin{array}{c}\text { 2-Year/5-Year } \\
\text { Event Rate }\end{array}$ & $\mathbf{N}$ & $\begin{array}{l}\text { 2-Year/5-Year } \\
\text { Event Rate }\end{array}$ & & \\
\hline \multicolumn{7}{|l|}{ Arrhythmic Death or Cardiac Arrest } \\
\hline Registry patients $\dagger$ & 1,174 & $0.12 / 0.25$ & 223 & $0.13 / 0.23$ & $1.03(0.73,1.45)$ & 0.87 \\
\hline No electrophysiologically guided therapy & 319 & $0.18 / 0.34$ & 34 & $0.13 / 0.21$ & $0.69(0.29,1.61)$ & 0.39 \\
\hline Electrophysiologically guided therapy & 317 & $0.12 / 0.25$ & 34 & $0.09 / 0.26$ & $0.88(0.35,2.23)$ & 0.78 \\
\hline \multicolumn{7}{|l|}{ Total Mortality } \\
\hline Registry patients $\dagger$ & 1,174 & $0.20 / 0.44$ & 223 & $0.27 / 0.47$ & $1.19(0.95,1.49)$ & 0.13 \\
\hline No electrophysiologically guided therapy & 319 & $0.29 / 0.50$ & 34 & $0.24 / 0.34$ & $0.71(0.39,1.30)$ & 0.27 \\
\hline Electrophysiologically guided therapy & 317 & $0.21 / 0.41$ & 34 & $0.32 / 0.53$ & $1.51(0.86,2.64)$ & 0.15 \\
\hline
\end{tabular}

*Adjusted for induction of randomizable ventricular tachycardia, age, ejection fraction, race, prior myocardial infarction, prior coronary artery bypass graft surgery, prior percutaneous intervention (PCI), number of diseased vessels ( $>75 \%$ stenosed), digitalis at baseline, intraventricular conduction delay, left bundle branch block, angina within 6 weeks of enrollment, longest episode of nonsustained ventricular tachycardia.

$\dagger$ Noninducible registry patients. 
All Patients

Overall Survival

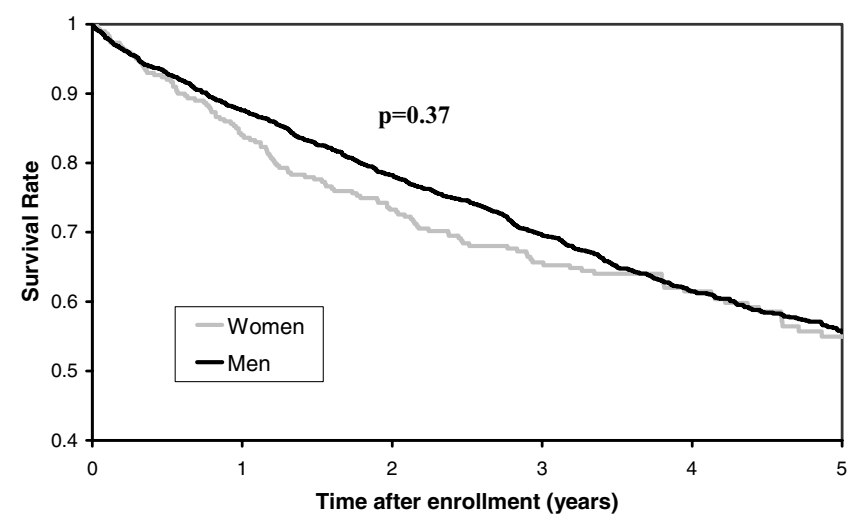

Figure 2. Overall survival in all patients. There was no significant difference in 5-year overall survival for women compared to men in the randomized and registry groups examined together $(P=0.37)$.

With respect to the type of EP-guided therapy, we did not observe gender bias related to ICD implantation rates in the current primary prevention trial. This is similar to previous secondary prevention trials, which demonstrated no significant gender differences in ICD implantation rates. ${ }^{15,16}$ In the present study, there were no differences with respect to ICD recommendations or refusal in women compared to men. In contrast, women refused ICD implantation more often than men $(19 \%$ vs $2 \%, \mathrm{P}=0.01)$ in one previous study. ${ }^{21}$

In the current study, there appeared to be no gender differences with regard to overall mortality or occurrence of arrhythmic death or cardiac arrest, despite gender differences in baseline characteristics and inducibility. Similar to the current analysis, mortality was similar in women $(14.4 \%)$ and men (15.5\%) in AVID, a secondary prevention trial, despite gender differences in baseline characteristics and clinical arrhythmia at the time of presentation. ${ }^{15}$ In a retrospective review of patients enrolled in clinical studies designed to evaluate new ICDs or defibrillation leads, Pires et al. ${ }^{22}$ demonstrated that men and women with a variety of clinical presentations and types of heart disease had similar sudden and cardiac deathfree survival rates during a mean follow-up period of $<1$ year. Consistent with the current study, MADIT II demonstrated that the benefit of defibrillator therapy on survival was similar in men and women with coronary disease who underwent device implantation for primary prevention. ${ }^{23}$

\section{Study Limitations}

This is a post hoc analysis of patients enrolled in MUSTT. The greatest limitation of this analysis is the small number of women enrolled in the trial, particularly the small number of women who received ICDs. Therefore, small differences in outcome may not be apparent.

\section{Conclusion}

Marked differences in inducibility of sustained VT, as well as other differences in characteristics between men and women, were observed in this trial. Despite these gender differences, EP-guided therapy, which includes a relatively "nonspecific" treatment with ICD implantation, appears to offer equal protection against arrhythmic death in men and women. Although the small number of women in this trial makes it difficult to draw any firm conclusions regarding gender differences in outcome, these results should be viewed as interesting preliminary data that are hypothesis-generating for examination in future trials. Risk stratification in women may need to be reconsidered to reflect that fact that women less often have inducible VT and often have a higher ejection fraction despite a more frequent history of heart failure. Further investigation also is warranted to determine whether gender differences in outcome might be apparent with different arrhythmia substrates or other types of heart disease, including patients with nonischemic dilated cardiomyopathy. Other multicenter primary prevention trials, such as the Sudden Cardiac Death in Heart Failure Trial (SCD-HeFT), may help answer these questions.

\section{References}

1. Steingart RM, Packer M, Hamm P: Sex differences in the management of coronary artery disease. N Engl J Med 1991;325:226-230.

2. Ayanian JZ, Epstein AM: Differences in the use of procedures between women and men hospitalized for coronary heart disease. N Engl J Med 1991;325:221-225.

3. Maynard C, Althouse R, Cerqueiva M, Olsufka M, Kennedy JW: Underutilization of thrombolytic therapy in eligible women with myocardial infarction. Am J Cardiol 1991;68:529-530.

4. Tobin JN, Wassertheil-Smoller S, Wexler JP, Steingart RM, Budner N, Lense L, Wachspress J: Sex bias in considering coronary bypass surgery. Ann Intern Med 1987;107:19-25.

5. Khan S, Nessim S, Gary R, Czer LS, Chaux A, Matloff J: Increased mortality of women in coronary artery bypass surgery: Evidence for referral bias. Ann Intern Med 1990:561-567.

6. Chiriboga DE, Yarzebski J, Goldberg RJ, Chen Z, Gurwitz J, Gore JM, Alpert JS, Dalen JE: A community-wide perspective of gender differences and temporal trends in the use of diagnostic and revascularization procedures for acute myocardial infarction. Am J Cardiol 1993;71:268273.

7. Becker RC, Terrin M, Ross R, Knatterud GL, Desvigne-Nickens P, Gore JM, Braunwald E: Comparison of clinical outcomes for men and women with myocardial infarction. Ann Intern Med 1994;120:638645.

8. Krumholz HM, Douglas PS, Lauer MS, Pasternak RC: Selection of patients for coronary angiography and revascularization after myocardial infarction: is there evidence for a gender bias? Ann Intern Med 1992;116:785-790.

9. Bickell NA, Pieper KS, Lee KL, Mark DB, Glower DD, Pryor DB, Califf RM: Referral patterns for coronary artery disease treatment: Gender bias or good clinical judgment. Ann Intern Med 2002;116:791-797.

10. Mark DB, Shaw LK, DeLong ER, Califf RM, Pryor DB: Absence of sex bias in the referral of patients for cardiac catheterization. N Engl J Med 1994;330:1101-1106.

11. Schatzkin A, Cupples A, Heeren T, Morelock S, Kannel WB: Sudden death in the Framingham heart study: Differences in incidence and risk factors by sex and coronary status. Am J Epidemiol 1984;120:888-899.

12. Kannel WB, Schatzkin A: Sudden death: Lessons from subsets in population studies. J Am Coll Cardiol 1985;5:141B-149B.

13. Buxton AE, Lee KL, Fisher JD, Josephson ME, Prystowsky EN, Hafley G, for the Multicenter UnSustained Tachycardia Trial Investigators. A randomized study of the prevention of sudden death in patients with coronary artery disease. N Engl J Med 1999;341:1882-1890.

14. Buxton AE, Fisher JD, Josephson ME, Lee KL, Pryor DB, Prystowsky EN, Simson MB, DiCarlo L, Echt DS, Packer D, and the MUSTT Investigators: Prevention of sudden death in patients with coronary artery disease: The Multicenter UnSustained Tachycardia Trial (MUSTT). Prog Cardiovasc Dis 1993;36:215-226.

15. Engelstein ED, Friedman PL, Yao Q, Coromilas J, Beckman KJ, Buxton AE, Flynn D, Firth B, Delamaga H, Ledingham R, Schron EB: Gender differences in patients with life-threatening ventricular arrhythmias: Impact on treatment and survival in the AVID trial. Circulation 1997;96(Suppl):I-720.

16. Albert CM, McGovern BA, Newell JB, Ruskin JN: Sex differences in cardiac arrest survivors. Circulation 1996;93:1170-1176. 
17. Freedman RA, Swerdlow CD, Soderholm-Difatte V, Mason JW: Prognostic significance of arrhythmia inducibility or noninducibility at initial ep study in survivors of cardiac arrest. Am J Cardiol 1988;61:578582.

18. Kim C, Fahrenbruch CE, Cobb LA, Eisenberg MS: Out-of-hospital cardiac arrest in men and women. Circulation 2001;104; 2699-2703.

19. Schoenfeld MH, McGovern B, Garan H, Kelly E, Grant G, Ruskin JN: Determinants of the outcome of electrophysiologic study in patients with ventricular tachyarrhythmias. J Am Coll Carrdiol 1985;6:298-306.

20. Vaitkus PT, Kindwall E, Miller JM, Marchlinski FE, Buxton AE, Josephson ME: Influence of gender on inducibility of ventricular arrhythmias in survivors of cardiac arrest with coronary artery disease. Am J Cardiol 1991;67:537-539.
21. Horton HL, Marinchak RA, Rials SJ, Kowey PR: Gender differences in device therapy for malignant ventricular arrhythmias. Arch Intern Med 1995; 155:2342-2345.

22. Pires LA, Sethuraman B, Guduguntla VD, Todd KM, Yamasaki H, Ravi S: Outcome of women versus men with ventricular tachyarrhythmias treated with the implantable cardioverter defibrillator. J Cardiovasc Electrophysiol 2002:563-568.

23. Moss AJ, Zareba W, Hall J, Klein H, Wilber DJ, Cannom DS, Daubert JP, Higgins SL, Brown MW, Andrews ML, and the Multi-center Automatic Defibrillator Implantation II Trial Investigators: Prophylactic implantation of a defibrillator in patients with myocardial infarction and reduced ejection fraction. N Engl J Med 2002;346:877883. 